\title{
The bigger picture
}

Stephen Hancocks OBE

Editor-in-Chief

We work in small spaces, literally and metaphorically. Our professional expertise is focussed on one small area of the body and in practical terms we often find ourselves working in fairly physically confined surroundings as well. In the shorthand parlance for which estate agents are famed, we and our premises might be euphemistically termed compact. It is perhaps not such a bad thing then to be reminded from time to time of a bigger picture, a larger landscape.

One of the research summaries in this issue reports the work consequent upon just such an awareness of wider considerations. ${ }^{1}$ The authors had noticed that the type of patients attending a dental access centre had a different health and social profile to those who might be found attending general or family practice, particularly on a regular basis. In concert with this awareness came the observation that the patients also had a higher consumption of tobacco and alcohol making them potentially at greater risk from mouth cancer.

The clinicians then took the further step of suggesting that such visits to a health professional, more infrequent by definition, might provide the opportunity to give health education advice specifically on this disease and the risk factors that predispose to it. Reality has so far swerved around the neat logic that this solution might initially have promised but this is less important than the potential power for development prompted by the proposition. It is also a timely reminder of Mouth Cancer Awareness Week which latches into its important annual slot in the calendar next month. Part of the difficulty in raising awareness of this distressing disease stems from the population at risk, its attitudes and lifestyles and part from the nature of the condition and its presenting symptoms. It is disappointing that the incidence of advanced versus early mouth cancer at diagnosis has improved little in recent years despite time and effort on education, health promotion and raising awareness.

\section{SOCIAL DETERMINANTS AND ORAL DISEASE}

It does, however, highlight once again in terms of the wider horizon the role that social determinants play in illness and disease. A fascinating insight of this came to light recently when figures for cancers in general in the UK were released in the form of a geographical representation. There was a concentration of some carcinomas in patients along the South Coast of England, which was not entirely surprising given the older population in that region who gravitate there to retire. What was striking though was that these areas also had the highest cure rates and in comparison to other parts of the UK, the longest post-diagnosis survival. Part of the reason has to be the type of patients. Well informed and more aware of preventive behaviours, as well as more attuned to the signs and symptoms, the higher socio-economic groups that, broadly, form these populations seek early advice, are possibly more demanding of access to good care and consequently are able to avail themselves of the greater benefits that accrue.

This link between health, environment and economics was brought into sharp relief at the recent FDI Congress in Stockholm with a remarkable presentation by Hans Rosling entitled 'Oral health - a global perspective - or has the world become a better place?' Using some very clever software and indulging his obvious and enviable flair for showmanship, Dr Rosling enchanted his very large audience with computer graphics that showed international trends in disease prevalence. These charts literally moved in front of our eyes as caries for example, was shown to have shifted markedly in different nations over the past fifty years. Spellbinding as this technological wizardry was, the greater fascination was the mapping of this data onto other trends such as the number of children in families, dropping to an unexpected extent throughout the world, and rising gross national product per head of population.

Our greater awareness nowadays consequent upon increased knowledge as well as the means to track, analyse and more easily communicate it means that the hunches that we once held can now be given flesh and bones. So, the analysis of the incidence, risk factors, aetiology and social profile of mouth cancer as a pertinent example enable greater targeting and no doubt in due time will bring improved results.

Just because we operate in confined surroundings does not mean that we should restrict our view of the world around us. By nurturing a broader awareness we can find greater personal fulfilment as well as the potential to discover improved and more imaginative ways to better serve our patients, their health and their welfare.

1. Williams $\mathrm{M}, \mathrm{Scott} \mathrm{S}$. Is there scope for providing oral cancer health advice in dental access centres? Br Dent J 2008; 205: E16

DOI: $10.1038 /$ sj.bdj.2008.901 